\title{
AS TECNOLOGIAS DE INFORMAÇÃO E COMUNICAÇÃO NOS ESPAÇOS URBANOS GLOBAIS E A PROPOSIÇÃO DE CIDADES INTELIGENTES
}

\author{
Thami Covatti Piaia \\ Universidade Regional Integrada do Alto Uruguai e das \\ Missões (URI), Santo Ângelo, Rio Grande do Sul \\ thamicovatti@hotmail.com \\ Elenise Felzke Schonardie \\ Universidade Regional do Noroeste do Estado do Rio \\ Grande do Sul (UNIJUÍ), Rio Grande do Sul \\ elenise.schonardie@unijui.edu.br
}

RESUMO: O presente texto ocupa-se do tema das novas tecnologias e suas implicações nos espaços urbanos globais. Tem por objetivo principal, demonstrar a importância das tecnologias de informação e comunicação - TICs e seus impactos na sociedade a partir do impulso da informatização sobre as culturas em nível global e do conceito de sociedade em rede que, de certo modo, pode sintetizar as características do mundo contemporâneo, acentuadamente globalizado e tecnologicamente desenvolvido. Inicialmente, apresenta considerações pontuais pertinentes às reconfigurações sociais do mundo globalizado. Na sequência, expõe sobre a relação entre as TICs e os espaços urbanos globais para a proposição de cidades inteligentes. E, por fim, explora a conexão entre as novas tecnologias e as instituições, em uma perspectiva de inovação e desenvolvimento, mas não excludente dos seres humanos.

PALAVRAS-CHAVE: Cidades inteligentes. Espaços urbanos globais. Tecnologias de informação e comunicação.

\section{Information and communication technologies in global urban spaces and the proposition of smart cities}

\begin{abstract}
This text is about new technologies and their implications in global urban spaces. It has as its main goal, to show the importance of information and communication technologies - ICTs and their impacts on society through the process of informatization of cultures globalwise and the concept of net society, which, by its turn, can amass characteristics of the contemporary world. Which are, to be, globalized and technologically developed. Initially, it presents specific considerations about social reconfigurations in the globalized world. Followed by an exposition about the relationship between ICTs and global urban spaces regarding the propositon of smart cities. Finally, it explores the connection between new technologies and institutions, in a new light upon innovation and development, which does not excludes human beings.
\end{abstract}

KEYWORDS: Smart cities. Global urban spaces. Information and communication technologies. 
As tecnologias de informação e comunicação nos espaços urbanos globais e a proposição de cidades inteligentes

\section{INTRODUÇÃO}

O mundo contemporâneo convive com o fenômeno de uma globalização tecnológica acentuada, significando que as sociedades estão sob o impacto da informatização sobre suas culturas. E, mais do que isso, as transformações oriundas da globalização, em que o local e as distâncias foram neutralizados pelas tecnologias de informação e comunicação - TICs e pela hipermobilidade de fluxos de capitais, de produtos e de pessoas, com significativo impacto sobre as instituições, os Estados nacionais e as sociedades, fizeram eclodir um mundo novo.

E, nesse mundo novo que se configurou a partir do avanço exponencial das ciências de um modo geral - nas primeiras décadas do século XXI -, há o protagonismo das tecnologias de informação e comunicação - TICs. Não resta dúvida que as TICs oportunizaram melhoras significativas para a vida em sociedade, no entanto, há questionamentos, riscos e vulnerabilidades suscitadas em razão do surgimento das TICs, como por exemplo, seus impactos sobre as populações humanas em situação de vulnerabilidade social ou econômica, ou, ainda, em relação ao papel dos seres humanos frente às significativas modificações sociais, laborais e culturais.

Nesse diapasão, o presente artigo aborda o tema das novas tecnologias e suas implicações nos espaços urbanos globais, uma vez que a concentração humana nas cidades tem crescido significativamente e com forte prognóstico de contínuo adensamento para as próximas décadas. Desse modo, objetiva-se principalmente, demonstrar a importância das tecnologias de informação e comunicação - TICs e seus impactos na sociedade a partir do impulso da informatização sobre as culturas em nível global e do conceito de sociedade em rede que, de certo modo, pode sintetizar as características do mundo contemporâneo, acentuadamente globalizado e tecnologicamente desenvolvido.

Para tanto, a pesquisa teórica que embasa o texto observou como método de abordagem o hipotético-dedutivo, de procedimento o bibliográfico e de interpretação o jurídico-sociológico, na medida em que se ocupa em demonstrar as conexões e imbricações teóricas de sociólogos, juristas, cientistas políticos e economistas.

\section{GlobalizaÇÃo TeCNOLÓGiCA}

O nosso mundo e a nossa vida mudaram muito e em pouco tempo. Essas mudanças são decorrência do fenômeno mais dinâmico e complexo que aconteceu em nível global, que modificou e continua a modificar o mundo a nossa volta: a globalização, ou seja, o modo como vivemos agora, alerta-nos Anthony Giddens. A globalização é política, tecnológica e cultural, tanto quanto econômica. Foi influenciada acima de tudo por desenvolvimentos nos sistemas de comunicação que remontam apenas ao final da década de 1960 (GIDDENS, 2005, p.21), sendo um conjunto complexo de processos que operam de forma contraditória ou antagônica, em escalas multiníveis, neutralizando o lugar e a distância, favorecendo a mobilidade de capitais e de pessoas (estas com algumas reservas em razão de sua origem e posição econômica) e a comunicação global.

A globalização é tecnológica, pois dissemina discricionariamente bens, produtos e sistemas que passam a integrar a vida das pessoas, independentemente de suas escolhas. A comunicação eletrônica instantânea não é apenas um meio pelo qual notícias ou informações são transmitidas mais rapidamente. Sua existência altera a própria estrutura de nossas vidas, quer sejamos ricos ou pobres. Quando a imagem de Nelson Mandela pode ser mais familiar para nós que o rosto do nosso vizinho de porta, alguma coisa mudou na natureza da experiência cotidiana. (GIDDENS, 2005, p.22) 
Não obstante, o fenômeno da globalização está influenciando aspectos íntimos e pessoais da vida cotidiana, não sendo apenas algo externo, que acontece lá fora (e longe), mas algo que modifica a forma de observar, refletir e confabular o mundo ao nosso redor. Isto porque, em muitos casos é mais comum as pessoas passarem longas horas de seu dia, comunicando-se via rede internacional de computadores com pessoas há centenas ou milhares de quilômetros de distância, do que contatarem seu vizinho mais próximo.

Essa nova forma de organização social, que penetra todos os níveis da sociedade e, que se difundiu mundialmente, tem abalado instituições, transformado culturas, criando riquezas e induzindo pobreza, incitando a inovação e a esperança, tanto quanto a ganância e a desesperança. Para Manuel Castells (2006) a globalização ocasionou a transformação das bases materiais da vida. O tempo e o espaço foram demudados mediante a criação de um espaço de fluxos e de um tempo intemporal como expressões das atividades das elites dominantes.

\begin{abstract}
A revolução da tecnologia da informação e a reestruturação do capitalismo introduziram uma nova forma de sociedade, a sociedade em rede. Essa sociedade é caracterizada pela globalização das atividades econômicas decisivas do ponto de vista estratégico; por sua forma de organização em rede; pela flexibilidade e instabilidade do emprego e a individualização da mão-de-obra. Por uma cultura da virtualidade real construída a partir de um sistema de mídia onipresente, interligado e altamente diversificado. (CASTELLS, 2006, p. 17).
\end{abstract}

A globalização e a tendência para a política de descentralização também estão intimamente ligadas à mudança de paradigma, com novas possibilidades e da forma mais eficaz para tirar proveito (PEREZ, 2001) em uma sociedade em rede, caracterizada por um modelo reticular no qual a informação navega de forma distribuída, horizontal, dialógica e redundante e onde cada nó tem igual importância e poder de interdependência. (DI FELICE, 2012, p. 30)

Pode-se considerar então, que a descrição revoluções tecnológicas schumpeterianas como processos de "destruição criativa" não se aplica apenas à economia, mas também para as políticas e instituições. (PEREZ, 2001, p.123) Se a era industrial foi caracterizada pelo acúmulo de capital e de propriedade, a nova era valoriza as formas intangíveis de poder vinculadas a conjuntos de informações e ativos intelectuais. $\mathrm{O}$ fato é que os produtos tangíveis, que durante muito tempo foram uma medida de riqueza no mundo industrial, estão se desmaterializando. (RIFKIN, 2001, p.25)

Desde o surgimento da tecnologia da internet, que permitiu a troca instantânea de informações e conhecimento entre pessoas de todas as partes do planeta, aconteceu um incrível intercâmbio de mercadorias, serviços, tecnologias e pessoas em várias partes do mundo. As batalhas, que até então tiveram caráter bélico, são cada vez mais econômicas e as lutas são travadas no ringue do mercado mundial, completamente globalizado. Para Sidekum (2003), a cultura contemporânea tem dimensões de grandiosidade universal pelas redes da globalização da comunicação e possui possibilidades que extrapolariam o imaginário dos visionários de alguns séculos atrás. Cada revolução tecnológica é onipresente e fornece tecnologias genéricas e novas práticas organizacionais que levam a aumentos significativos no potencial da maioria das atividades produtivas existentes. Os princípios subjacentes a este processo se incorporam gradualmente à modernização de um modelo de boas práticas que chamamos de "estilo tecnológico" ou "paradigma tecnoeconômico". O resultado é um rejuvenescimento gradual de toda a estrutura produtiva, para que as indústrias maduras possam voltar a se atualizar conforme novas indústrias, em termos de dinamismo, produtividade e rentabilidade. (PEREZ, 2001, p.123)

Um paradigma tecnoeconômico, preceitua Perez, articula os modelos técnicos e organizacionais para maximizar o potencial da revolução tecnológica correspondente. Cada paradigma fornece um novo conjunto de princípios de "senso comum" que servem para orientar a tomada 
As tecnologias de informação e comunicação nos espaços urbanos globais e a proposição de cidades inteligentes

de decisões de empreendedores, inovadores, gestores, administradores, engenheiros e investidores para a máxima eficiência e eficácia, tanto em novas atividades, como nas velhas. (PEREZ, 2001, p.123) Quanto maior o número e maior a complexidade das tecnologias específicas já instaladas, mais arraigadas são as ligações entre eles e mais abundante é o estoque de recursos humanos qualificados, maior a possibilidade de aplicar com sucesso o novo paradigma para renovar a base produtiva e dar um salto em frente. Isso significa que os países que não conseguiram atingir uma massa crítica em termos de experiência e capacidade industrial sob o paradigma anterior, podem enfrentar uma janela muito estreita de oportunidades para tirar partido das novas tecnologias. (PEREZ, 2004, p.40) O processo de propagação de cada onda, ou paradigma tecnológico passa por quatro períodos distintos: de difusão inicial, de rápido crescimento inicial, rápido crescimento tardio e maturação. Uma vez que isso ocorre em países que estão na vanguarda onde se implanta o paradigma aspirado, os países retardatários devem fazer frente a estes conjuntos de oportunidades. (PEREZ, 1992, p.31)

As inovações, nos ensinam North e Thomas, podem criar mudança social, e a subsequente mudança social pode trazer inovações adicionais que podem reagir sobre as estruturas e/ou funções alteradas que as fizeram existir ou influenciam o mercado, de produtos, serviços, processos, métodos e sistemas que não existiam anteriormente ou que contenham alguma característica nova e diferente do padrão em vigor. (NORTH; THOMAS, 1973, p.154-155)

Assim sendo, em um contexto de diversas mudanças ligadas à globalização tecnológica, em razão das muitas formas de informatização observamos o surgimento e ascensão de escalas subnacionais, como no caso das cidades globais, e supranacionais, como no caso dos mercados globais, onde anteriormente dominava apenas a escala nacional (SASSEN, 2010). E esta ascensão de diferentes escalas impactaram a capacidade regulatória dos Estados e tem suscitado muitas dúvidas quanto à real possibilidade de participação democrática nas decisões que influenciam, diretamente, a vida cotidiana das pessoas nas cidades. Os avanços tecnológicos oportunizados e disseminados pelos complexos, dinâmicos e diversos processos advindos do fenômeno da globalização, acabaram por alterar o mundo, na forma como este se estabeleceu na modernidade, em que o centro do mundo político estava na figura do Estado-nação e seus limites territoriais. Uma nova configuração se estabeleceu, não apenas em relação ao mundo político e regulatório, mas, igualmente, em relação a forma de viver e se relacionar das pessoas.

A rápida proliferação de redes computadorizadas globais e a informação de uma ampla variedade de atividades econômicas e políticas que proporcionam que elas circulem nessas redes levantaram questões sobre a efetividade das atuais estruturas para a autoridade estatal e a participação democrática. [...] seu potencial para enfraquecer a autoridade estatal da maneira como vem se constituindo nos dois últimos séculos. (SASSEN, 2010, p. 67).

Com isso, novos atores surgem em escala global e passam a controlar mercados, influenciar a cultura local e a capacidade de regulação dos Estados. Dentre esses novos atores temos, de um lado os organismos internacionais como por exemplo a Organização das Nações Unidas - ONU, a Organização Internacional do Trabalho - OIT, a Organização Mundial do Comércio - OMC entre outras; de outro as empresas transnacionais para as quais as TICs, são fundamentais para sua existência e capacidade de proliferação e reprodução do capital financeiro em nível global.

Como afirmado na introdução deste articulado, nosso interesse não está em enaltecer ou tão somente criticar as novas tecnologias de informação e comunicação, mas sim, em provocar a reflexão sobre como essas inovações impactam a atual sociedade em rede nos espaços urbanos globais. Como tornar acessível o contato e a utilização desses sistemas interligados que nos mantêm conectados com os mais diversos locais do globo terrestre? Como as instituições podem 
contribuir para o desenvolvimento tecnológico de um país e para a transformação de espaços urbanos globais em cidades inteligentes, pacificando conflitos, revitalizando culturas e mercados locais, para a melhoria da qualidade de vida das pessoas, reduzindo desigualdades, auxiliando a mobilidade, quiçá até, proporcionando um mais amplo bem-estar social nos espaços urbanos globais.

\section{ESPAÇOS URBANOS GLOBAIS}

Há locais estratégicos ao grande capital, em que todas as tecnologias de informação e comunicação estão disponíveis e a serviço dos conglomerados empresariais transnacionais e de parcela economicamente privilegiada da população: os espaços urbanos globais. As cidades consideradas globais caracterizam-se por ser um centro de tomada de decisões, são locais estratégicos para a hipermobilidade do grande capital e de ativos financeiros e as decisões tomadas nesses centros são espraiadas para todo o globo. São locais de alta densidade populacional, contudo, há a presença de uma classe internacional de profissionais e ambientes de negócios altamente internacionalizados, de altíssima remuneração, que se destaca e que necessitam de sistemas e tecnologias de ponta. Segundo Sassen (2010), as cidades globais constituem pontos nodais de poder das empresas e corporações transnacionais, e esse poder não é apenas econômico, mas condiciona o político, na medida em que pressiona o Estado e suas instituições objetivando a desregulamentação para livre mobilidade do capital, influenciando a produção do direito - da lei. Nas cidades consideradas globais há alta intensidade tecnológica, pois nelas encontramos uma alta aceleração de fluxos (pessoas, capital e mercadorias) que operam 24 horas, ou seja, são cidades que não dormem. ${ }^{1}$

Embora as TICs sejam fundamentais para as cidades globais, elas não estão adstritas a esses lugares, dessa forma, um novo conceito de cidade, voltado à dinamização de TICs vem ganhando espaço nas discussões locais. A cidade inteligente ou smart city ${ }^{2}$ é um conceito ainda em construção que vem chamando atenção não apenas por parte dos gestores públicos, mas da população como um todo, na medida em que as comunidades estão procurando aliar a reivindicação de acesso às novas TICs para a melhoria dos processos locais relacionados às dinâmicas da vida nos espaços urbanos.

Existe uma variedade de conceitos e definições sobre a cidade inteligente, mas basicamente sua abordagem pode ser reduzida a duas; a) uma abordagem baseada em tecnologias, centrada em infraestruturas físicas urbanas; ou b) uma abordagem holística centrada no cidadão e nos inúmeros componentes interligados que caracterizam o sistema urbano (RIZZON; BERTELLI; MACKE et al. 2020, p. 127). Quanto às características ou dimensões que uma cidade precisa demonstrar para ter alta performance, também, encontramos diferenças conceituais.

Por exemplo, para uns autores ou organismos uma cidade inteligente terá de apresentar seis dimensões com alto desempenho, sendo: economia inteligente; pessoas inteligentes; governança inteligente; mobilidade inteligente; ambiente inteligente e vida inteligente (GIFFINGER et al, 2007 apud RIZZON; BERTELLI; MACKE et al. 2020). E, para outros, como o Cities in

1 Dentre as cidades globais podemos citar New York, Londres, Tóquio, Frankfurt, Hong Kong, Paris, Milão, Pequim, São Paulo, Chicago, Sidney, Cidade do México entre outras. Atualmente existem mais de 70 no mundo, que podem ser consideradas como globais.

2 Segundo RIZZON; BERTELLI; MACKE et al. (2020, p. 126) "O termo Smart City foi criado no início dos anos noventa a fim de conceituar o fenômeno de desenvolvimento urbano dependente de tecnologia, inovação e globalização, principalmente em uma perspectiva econômica (Gibson, Kozmetsky, \& Smilor, 1992). Na segunda metade da década de 2000, com o estudo de Giffinger, Fertner, Kramar, Kalasek, Pichler-Milanović and Meijers (2007), o conceito de Smart City ganhou amplitude no debate científico." 
As tecnologias de informação e comunicação nos espaços urbanos globais e a proposição de cidades inteligentes

Motion Index, do IESE Business School na Espanha, dez dimensões são consideradas para indicar o nível de inteligência de uma cidade: governança, administração pública, planejamento urbano, tecnologia, o meio-ambiente, conexões internacionais, coesão social, capital humano e a economia (FUNDAÇÃO GETÚLIO VARGAS, 2020).

As chamadas cidades inteligentes, são expressão de um modelo econômico particularizado, com visão moderna do desenvolvimento urbano e que adotam as TICs no direcionamento da competitividade econômica, sustentabilidade ambiental e qualidade de vida, que se adotarem uma abordagem apenas tecnológica estarão voltadas para criação de um ambiente de inovações tecnológicas no qual será possível realizar a integração inteligente dos setores que envolvem a cidade. No entanto, se adotarem uma abordagem holística a utilização das TICs servirá para melhorar a ampla prestação de serviços urbanos. Nesta perspectiva, o uso das novas TICs será direcionado para o processo de planejamento urbano com a participação dos cidadãos, isto significa o uso da tecnologia voltado para a inclusão social no espaço urbano. Segundo a União Europeia, smart cities são sistemas de pessoas interagindo e usando energia, materiais, serviços e financiamento para catalisar o desenvolvimento econômico e a melhoria da qualidade de vida. Esses fluxos de interação são considerados inteligentes por fazer uso estratégico de infraestrutura e serviços e de informação e comunicação com planejamento e gestão urbana para dar resposta às necessidades sociais e econômicas da sociedade. (FUNDAÇÃO GETÚLIO VARGAS, 2020)

Um aspecto interessante a ser considerado é que a noção de cidade inteligente está imbricada na de cidade sustentável. Isso significa que a utilização das TICs está sendo aplicada e incentivada a serem utilizadas para dinamizar os espaços urbanos, contribuir para a melhoria da qualidade de vida das pessoas que transitam, trabalham e vivem nesses espaços, bem como, otimizar a utilização dos recursos ambientais necessários para o funcionamento das cidades. Cidades sustentáveis e/ou inteligentes são aquelas que se desenvolvem de maneira planejada (mensuráveis por intermédio de indicadores básicos como economia, mobilidade, qualidade de vida) e que, segundo dados do ranking "Connected Smart Cities", na pesquisa "Urban Systems", cuja avaliação é pautada por critérios de inteligência, conexão e sustentabilidade econômica e ambiental, estão atreladas também à inovação na aplicação dos instrumentos legais já existentes. (GOMES; ZAMBAM, 2020, p. 328)

É importante destacar que uma cidade é inteligente quando o investimento em capital humano e social e a infraestrutura de TICs são elementos para o crescimento econômico e uma elevada qualidade de vida, "com uma gestão racional dos recursos naturais, através de uma governança participativa, ou seja, envolve a participação inteligente dos citadinos e o desenvolvimento sustentável local" (ARAÚJO; GUIMARÃES; COSTA, 2020). Uma cidade, para ser inteligente, precisa estar estruturada em capital físico e humano.

Como bem enfatiza Gala (2003), a grande distância observada ainda hoje entre países pobres e ricos encontra-se muito mais em diferenças entre matrizes institucionais do que em problemas de acesso a tecnologias. Sociedades pobres encontram-se nessa situação justamente por não terem desenvolvido uma base de regras, leis e costumes capazes de estimular atividades economicamente produtivas, especificamente acumulação de capital e de conhecimento. (GALA, 2003, p.93) A matriz institucional consiste em uma rede interdependente de instituições e organizações políticas e econômicas que são caracterizadas por um massivo aumento de retornos. As organizações fundamentam sua existência para as oportunidades que provêm de um sistema institucional. As oportunidades oferecidas pela matriz institucional determinam os tipos de organizações que virão a existir. (NORTH, 2005, p.I)

Moses Abramovitz (1986, p. 387-388) chama isso de capacidade social. Tomando em conta a capacidade social, porém, esperamos que os desenvolvimentos antecipados pela hipótese 
sejam claramente demonstrados em comparações entre países, apenas se as capacidades sociais dos países sejam as mesmas. Pode-se dizer, portanto, que o potencial de um país para o crescimento acelerado é forte, não quando seu retardamento é desqualificado, mas quando é tecnologicamente defasado, porém socialmente avançado.

A combinação da lacuna tecnológica e a capacidade social definem o potencial para produtividade avançada pelo alinhamento de um país. (ABRAMOVITZ, 1986, p. 389-390) Dentro desse sistema de crenças subjacente à matriz institucional, uma questão importante seria a capacidade social criada por uma sociedade durante os anos de sua formação. A capacidade social seria uma maneira de as pessoas trabalharem em parceria, em grupos e organizações que constituem a sociedade civil, para a prossecução de planos comuns. No entanto, conseguir que a população de um país subordine interesses pessoais ao interesse da maioria, depende diretamente do nível de confiança existente entre a sociedade entre si e entre a sociedade e o governo. A confiança nasce deste compartilhamento de valores e apresenta, um significativo valor para uma sociedade. (FUKUYAMA, 1996)

Confiança é a expectativa que nasce no seio de uma comunidade de comportamento estável, honesto e cooperativo, baseado em normas compartilhadas pelos membros dessa comunidade. Essas normas podem ser sobre questões de valor profundo, como a natureza de Deus ou da justiça, mas também compreendem normas seculares, como padrões profissionais e códigos de comportamento. (FUKUYAMA, 1996. p.41)

Em contraste, aduz Fukuyama (1996), pessoas que não confiam umas nas outras acabarão cooperando somente num sistema de regras e regulamentos, que têm de ser negociados, acordados, litigiados, e postos em vigor muitas vezes por meios coercitivos. Esse aparato legal, servindo de substituto da confiança, acarreta o que os economistas chamam de "custos transacionais". (FUKUYAMA, 1996, p.44)

Antonny Giddens trata da questão da evolução dos ambientes de confiança e risco nas culturas modernas e pré-modernas, demonstrando que o bem-estar de uma nação, bem como a sua capacidade de associação, são condicionados por uma única e sutil característica cultural: o nível de confiança inerente à sociedade. (1991, p. 69) Primeiramente, a defasagem tecnológica não é um mero acidente. Características sociais, normalmente contam em certa porção, talvez a porção substancial de um país ao fracasso em alcançar grandes níveis de produtividade vis a vis países mais avançados. As mesmas deficiências, talvez de forma atenuada, normalmente continuam a conter um país menos desenvolvido na completude de seu ciclo tecnológico pela mera hipótese. (ABRAMOVITZ, 1986, p.387)

Países tecnologicamente defasados possuem o potencial para gerar crescimento mais rápido que países mais avançados, quando suas capacidades sociais forem suficientemente desenvolvidas para permitir a exploração bem-sucedida de tecnologias já empregadas pelos líderes tecnológicos. (ABRAMOVITZ, 1986, p.390) O passo no qual o potencial para alinhar-se é dado em um período particular depende de fatores limitadores de difusão de conhecimento, da taxa de mudança estrutural, acumulação de capital e expansão da demanda. (ABRAMOVITZ, 1986, p.390)

O capital institucional e humano componentes da capacidade social, se desenvolvem tão lentamente quanto a educação e a organização respondem a requisitos de oportunidade tecnológica e experiência em explorá-la. O seu grau de desenvolvimento age para limitar a força de tecnologias potencialmente adequadas. Além disso, o passo da realização de um potencial alinhamento depende do número de outras condições que governam a difusão de conhecimento, a mobilidade de recursos e a taxa de investimento. (ABRAMOVITZ, 1986, p.405-406) 
As tecnologias de informação e comunicação nos espaços urbanos globais e a proposição de cidades inteligentes

\begin{abstract}
As forças do mercado por si são vistas como pouco adequadas para a geração de eficiência, transferência e difusão de inovação. Governos possuem diversos papéis fundamentais e não-substituíveis no processo de promover a mudança tecnológica que pode tomar diversas formas: primeiramente, a atuação científica direta e atividades tecnológicas como no caso de universidades e outras instituições de pesquisas públicas; em segundo lugar, o suporte financeiro à inovação através do setor de negócios e em terceiro, o suprimento de infraestrutura de produção necessária, incluindo educação e treinamento, regras e normas e um sistema legal de propriedade intelectual para permitir que pessoas e empresas inovem. (ARCHIBUGIL; MICHIE, 2002, p.3)
\end{abstract}

O quadro institucional irá definir a direção da aquisição de conhecimento e habilidades, e essa direção será o fator decisivo para o desenvolvimento dessa sociedade a longo prazo. Se a empresa ou outra organização econômica investe em conhecimento, isso aumenta a produtividade dos insumos físicos ou de capital humano ou melhora o conhecimento tácito dos empreendedores, de forma que o aumento resultante na produtividade também é consistente com o crescimento da economia. (NORTH, 1990, p. 78) A matriz institucional resultante, afirma North, impõe severas limitações ao conjunto de escolhas dos empreendedores quando estes buscam inovar ou modificar as instituições de forma a melhorar suas posições políticas ou econômicas, (2005, p.2) consistindo em uma rede interdependente de instituições e consequentes organizações políticas e econômicas que são caracterizadas por lucros massivos crescentes. Ou seja, as organizações devem sua existência às oportunidades viabilizadas pelo quadro institucional. Ao longo do tempo, as crenças dominantes - aquelas dos empreendedores políticos e econômicos em posição de fazer as políticas - resultam na criação de uma elaborada estrutura de instituições formais e informais que determina o desempenho econômico e político dos países e da sociedade.

Por sua vez, a estrutura institucional, em qualquer momento, tem um efeito profundo sobre as tecnologias que estão em uso, e que estão sendo desenvolvidas. (NELSON; WINTER, 2002, p.23) A estrutura institucional age como um reflexo. Enquanto estrutura de incentivos das sociedades, as instituições produziram diversos induzimentos para investir, expandir e aplicar esse conhecimento crescente nos problemas da sociedade humana. (NORTH, 2005, p.43)

\footnotetext{
As características da matriz institucional, tanto as regras formais quanto informais demonstradas em atitudes e valores, podem produzir um meio político e econômico que premie as atividades produtivas e organizações desenvolvendo atitudes e conhecimentos. As estruturas institucionais nacionais são resultantes do processo histórico de desenvolvimento industrial e da modernização política, o que está diretamente associado à argumentação evolucionária das trajetórias tecnológicas, que levam em conta fatores essenciais como o processo de difusão da informação e o de geração de novas ideias. (CONCEIÇÃO, 2003, p.16)
}

Nelson (2008) questiona, portanto, como as instituições de um país são o que são. Em que medida pode uma reforma institucional salutar ser objeto de análise deliberada, planejamento e implementação? (Nelson, 2008, p.7) Os países diferem em seu sucesso econômico, afirmam Acemoglu e Robinson, por causa de suas diferentes instituições, as regras que influenciam a forma como a economia funciona e os incentivos que motivam as pessoas. (2012, p.73) Avner Greif (1998) acredita que as questões mais fundamentais sobre as instituições são: por que algumas sociedades evoluem ao longo de suas distintas trajetórias institucionais? Por que as sociedades falham ao tentar adotar a estrutura institucional das mais bem-sucedidas? Como nós podemos examinar as inter-relações entre os aspectos informais e implícitos das instituições de uma sociedade por um lado e seus aspectos explícitos e formais por outro? A resposta estaria, para Greif, na Historical and Comparative Institutional Analysis (HCIA). Uma análise institucional histórica e comparativa sobre os sistemas adotados por cada país e o método empírico utilizado, o HCIA explora a possibilidade que uma mudança institucional também reflete os limites sobre 
racionalidade, cognição, conhecimento e incentivos para mudanças institucionais e que as inovações adotadas e mudanças institucionais implicam sobre as instituições já existentes. (GREIF, 1998, p.82)

Não é somente o tipo de instituição que gerará um sistema em particular, diz Niosi, mas a coexistência de uma série de instituições, seu padrão de interação e a retroalimentação que receberão de seu entorno. (1993. p.218-219) A razão mais comum pela qual as nações falham atualmente é porque elas têm instituições extrativas. (ACEMOGLU; ROBINSON, 2012, p.368369) Instituições extrativas pavimentam o caminho para a falência completa do Estado, destruindo não só a lei e a ordem, mas também os incentivos econômicos mais básicos. O resultado é a estagnação econômica. (ACEMOGLU; ROBINSON, 2012, p.372)

Instituições políticas e econômicas, que são em última análise as escolhas da sociedade, podem ser inclusivas e incentivar o crescimento econômico. Ou podem ser extrativas e tornar-se empecilhos ao crescimento econômico. As nações falham quando elas têm instituições econômicas extrativas, apoiadas por instituições políticas extrativas que impedem e até mesmo bloqueiam o crescimento econômico, na compreensão dos autores. Os países se tornam Estados falhos não por causa de sua geografia ou sua cultura, pontuam Acemoglu e Robinson (2012), mas por causa do legado das instituições extrativas, que concentram poder e riqueza nas mãos daqueles que controlam o Estado, abrindo o caminho para a agitação, o conflito e a guerra civil. As instituições extrativas também contribuem diretamente para a gradual falência do Estado por negligenciar o investimento nos serviços públicos mais básicos. (2012, p.376)

De acordo com Douglass North, em seu livro Instituições, Mudança Institucional e Performance Econômica (1990), a causa da pobreza de uma nação, tanto relativa quanto absoluta, está no fato de esta ser vítima de uma estrutura institucional que não promove desenvolvimento. Do marco institucional derivam as classes de conhecimentos, destreza e aprendizado que requerem os membros de uma organização para atuarem eficientemente. Isto quer dizer que as limitações institucionais específicas ditam as margens conforme as quais operam as organizações e, por conseguinte, fazem inteligíveis as relações internas entre as regras do jogo e a conduta dos atores. Desde o início da década de noventa, North (1990) enfatizou a importância das right institutions como explicação central para o progresso econômico.

As nações falham economicamente por causa das instituições extrativas. Essas instituições mantêm pobres os países pobres e impedem-nos de embarcarem em uma trajetória para o crescimento econômico. (ACEMOGLU; ROBINSON, 2012, p.398) A base dessas instituições é uma elite que projeta instituições econômicas de forma a enriquecer-se e perpetuar o seu poder à custa da grande maioria das pessoas na sociedade. (ACEMOGLU; ROBINSON, 2012, p.399) A razão pela qual essas instituições extrativas persistem está sempre relacionada com o círculo vicioso, e as implicações dessas instituições em termos de empobrecer os seus cidadãos são semelhantes - mesmo que a sua intensidade difira. (ACEMOGLU; ROBINSON, 2012, p.399)

Nesse contexto, percebemos que as instituições políticas extrativas têm criado instituições econômicas extrativas, transferindo riqueza e poder para a elite dominante. Diferenças institucionais desempenham um papel crítico na explicação do crescimento econômico ao longo dos tempos, (ACEMOGLU; ROBINSON, 2012, p.124) sendo a configuração das instituições decisiva para determinar o desenvolvimento ou estagnação dos países e a transformação de espaços urbanos globais em cidades inteligentes, em que as TICs estarão a serviço dos cidadãos, não somente da parcela economicamente privilegiada, pois são as pessoas os principais agentes interessados na proposição do desenvolvimento de cidades inteligentes. Espera-se que as novas TICs, desenvolvidas e reguladas por instituições justas e inclusivas, moldem os espaços urbanos 
As tecnologias de informação e comunicação nos espaços urbanos globais e a proposição de cidades inteligentes

globais, auxiliando no desenvolvimento de capacidades harmoniosas para intervir e resolver problemas em governança com cidadãos empresas e governos, em prol da melhoria do ambiente e vida urbanos.

\section{CONSIDERAÇõES FinAis}

Objetivou-se neste trabalho, pôr em discussão temas relacionados às tecnologias de informação e comunicação - TICs e suas implicações nos espaços urbanos globais, ou seja, como as novas tecnologias, impulsionadas por uma acentuada globalização, poderiam transformar cidades globais em cidades inteligentes.

Restou demonstrado que para que espaços urbanos se tornem espaços globais inteligentes, não basta somente que se tenha avanços puramente tecnológicos, mas igualmente, que os países tenham instituições adequadas para que o desenvolvimento aconteça, harmonizando sociedade e tecnologia, humanos e máquinas, capital físico e social, criando uma capacidade de governança apta a tornar os espaços urbanos, cidades inteligentes, espaços de integração.

Cidades inteligentes voltadas ao bem-estar das pessoas que nelas habitam, com propostas de inclusão laboral e cultural, e não de exclusão, como sói acontecer, em que os privilegiados economicamente desfrutam de toda uma gama de benefícios trazidos pela riqueza e pela inovação tecnológica, ao passo que a outra parte da população, precisa conviver com a falta de conexão, estrutura e mobilidade nos centros urbanos da grande maioria dos países do mundo.

Infere-se, para finalizar, que deve haver uma conexão entre as tecnologias de informação e comunicação - TICs e as instituições, para proposição de cidades inteligentes, em uma perspectiva de inovação e desenvolvimento não excludente dos seres humanos.

\section{REFERÊNCIAS}

ABRAMOVITZ, M. Catching Up, Forging Ahead, and Falling Behind. The Journal of Economic History, v. 46, n. 2, p. 385-406, jun. 1986.

ACEMOGLU, D.; ROBINSON, J. A. Why Nations Fail: the origins of power, prosperity and poverty. New York: Crown Publishers, 2012.

ARAÚJO, D. da S.; GUIMARÃES, P. B. V.; COSTA, A. A. da. A implantação de cidades inteligentes no Nordeste brasileiro: um breve diagnóstico. In, Revista de Direito da Cidade. v. 12 n. 2. 2020, p. 153-173. Disponível em: https://www.e-publicacoes.uerj.br/index.php/rdc/article/ view/39957. Acesso em: 17 de jul. 2020.

ARCHIBUGIL, D.; MICHIE, J. Technical Change, Growth and Trade: new departure in institutional economics. Journal of Economics Surveys, v. 12, n. 3, 2002. p. 01-20.

CASTELLS, M. O poder da identidade (A era da informação: economia, sociedade e cultura). v. 2. São Paulo: Editora Paz e Terra, 2006.

CONCEIÇÃO, O. A. C. Elementos para uma Teorização Apreciativa Institucionalista do Crescimento Econômico: uma comparação das abordagens de North, Matthews e Zysman. Disponível em: http://www.anpec.org.br/encontro2003/artigos/A38.pdf. Acesso em: 10 ago. 2020.

DI FELICE, M. "Net-ativismo: novos aspectos da opinião pública em contextos digitais”. Revista Famecos, v. 19, n. 1. Porto alegre, 2012, p. 27-45. 
FUNDAÇÃO GETULIO VARGAS. O que é uma cidade inteligente. Disponível em: https:// fgvprojetos.fgv.br/noticias/o-que-e-uma-cidade-inteligente. Acesso em: 13 jul 2020.

FUKUYAMA, F. Confiança: as virtudes sociais e a criação da prosperidade. Tradução de Alberto Lopes. Rio de Janeiro: Rocco, 1996.

GALA, P. A Teoria Institucional de Douglass North. Revista de Economia Política. Vol.23, no2 (90), abril-junho de 2003. p. 89-105.

GIDDENS, A. As Consequências da Modernidade. São Paulo: UNESP, 1991.

GIDDENS, A. Mundo em descontrole. $4^{\mathrm{a}}$ ed. Rio de Janeiro: Record, 2005.

GOMES, D.; ZAMBAM, N. J. Sustentabilidade no espaço urbano: novas tecnologias e políticas públicas urbano-ambientais. In Revista de Direito da Cidade. v.10. n. 1. 2016, p. 310-334. Disponível em: https://www.e-publicacoes.uerj.br/index.php/rdc/article/view/29866/23349. Acesso em: 14 jul. 2020.

GREIF, A. Historical and Comparative Institutional Analysis. The American Economic Review, Palo Alto, v. 88, n. 2 May 1998. [Papers and Proceedings of the Hundred and Tenth Annual Meeting of the American Economic Association]

NELSON, R. R. What Enables Rapid Economic Progress: what are the needed institutions? Research Policy, New York, v. 37, p. 01-11, 2008.

NELSON, R. R.; WINTER, S. G. Evolutionary Theorizing in Economics. Journal of Economic Perspectives, v. 16, n. 2, p. 23-46, 2002.

NIOSI, J. National Systems of Innovation: in search of a Workable Concept. Technology in Society, v. 15, p. 207-227, 1993.

NORTH, D. C. Institutions, Institutional Change and Economic Performance. Cambridge: Cambridge University Press, 1990.

NORTH, D. C. Understanding the Process of Economic Change. Princeton: Princeton University Press, Princeton, 2005.

NORTH, D. C.; THOMAS, P. R. The Rise of the Western World: a new economic history. New York: Cambridge University Press, 1973.

PEREZ, C. Cambio Tecnológico y Oportunidades de Desarrollo como Blanco Móvil. Revista de la Cepal, Ciudad del Mexico, v. 75, p. 115-136, 2001.

PEREZ, C. Cambio Técnico, Restructuración Competitiva y Reforma Institucional en los Países en Desarrollo. El Trimestre Económico, Ciudad del Mexico, v.1, n. 233, p. 23-64, jan./mar. 1992.

PEREZ, C. Revoluciones Tecnológicas y Capital Financiero: la dinámica de las grandes burbujas financieras y las épocas de bonanza. México: Siglo XXI, 2004.

RIFKIN, J. A Era do Acesso. São Paulo: Makron Books, 2001.

RIZZON, F.; BERTELLI, J.; MACKE, J.; et al. Smart City: um conceito em construção. In Revista Metropolitana de Sustentabilidade. v. 7 n.3. Set./Dez. São Paulo, 2017, p. 123-142. Disponível em: http://revistaseletronicas.fmu.br/index.php/rms/article/view/1378. Acesso em: 15 jul. 2020 .

SASSEN, S. Sociologia da globalização. Porto Alegre: Artmed, 2010. 
As tecnologias de informação e comunicação nos espaços urbanos globais e a proposição de cidades inteligentes

SIDEKUM, A. Alteridade e Interculturalidade. In: SIDEKUM, Antônio (Org.). Alteridade e Multiculturalismo. Ijui: UNIJUÏ, 2003. p. 233-298.

Recebido em: 12 ago 2020.

Aceito em: 27 out. 2020. 